Proceedings

\title{
Prototype System for the Detection of Volatile Hydrocarbons in Water ${ }^{+}$
}

\author{
Alexey A. Vasiliev ${ }^{1, *}$, Mikhail Yu. Yablokov ${ }^{2}$ and Andrey V. Sokolov ${ }^{3}$ \\ 1 National Research Center "Kurchatov Institute", Kurchatov sq., 1, 123182 Moscow, Russia \\ 2 Enikolopov Institute of Synthetic Polymer Materials RAS, Profsoyuznaya st. 70, 117393 Moscow, Russia; \\ yabl1@yandex.ru \\ 3 OSTEK Enterprise Ltd., Kulakova, 20, 121467 Moscow, Russia; sok44@yandex.ru \\ * Correspondence: A-A-Vasiliev@yandex.ru; Tel.: +7-903-194-95-51 \\ + Presented at the Eurosensors 2018 Conference, Graz, Austria, 9-12 September 2018.
}

Published: 4 December 2018

\begin{abstract}
Detection of dissolved methane and volatile hydrocarbons in water is a problem met in leakage localization during exploitation of underwater pipelines, oil and oil product spill over water surface, geological exploration work for the localization of oil and gas fields under water, etc. This problem can be solved by the application of detection system based on tubular selective membrane permeable for volatile organics and impenetrable for liquid water. Carrier gas (air) flowing through this tube is saturated with dissolved gas and then gas concentration is measured using semiconductor or other gas sensor. The system prototype was tested under laboratory conditions and demonstrated low limit of gas detection ( 20 ppb by mass of dissolved methane in water) and short response time $(\sim 10 \mathrm{~s})$.
\end{abstract}

Keywords: volatile hydrocarbons; methane; water solution; gas sensor; system prototype; online monitoring

\section{Introduction}

The online detection of the concentration of hydrocarbons and, in particular, methane dissolved in water is an important problem. It is met in many cases, for ecological monitoring of the state of water sources, in the detection of leakage from gas and oil pipelines, one of very important applications of such system could be the discovery and delimitation of oil and gas fields. The last task is actual, because it is known that in gas and oil field there is leakage on the periphery of the field and in the middle of gas/oil containing structures.

In the moment, there are no simple and inexpensive instruments able to monitor the concentration of diluted oil and gas in water. The method, which is now in official use [1] (DIN ISO 9377-2: 2000) consists in the extraction of diluted hydrocarbons from water using organic solvent and further off-line analysis using laboratory methods, for example chromatography. Situation in Russian Federation is, in general, not better than in other countries. According to official documents, gas extraction chromatographic analysis of vapor phase requires approximately 1.8 man-hours for each analysis of probe.

The method, which was suggested in [2], consists in the application of small size spectrometer of mass dipped to water. The gas probing is performed using membrane unit. This instrument enables precise analysis of hydrocarbons and other gases, but this spectrometer is a bulky instrument, and can not be used in mass water analysis and monitoring systems.

We present the results of the prototyping of a system [3] including tubular pervaporation membrane, used for the separation of volatile organics from water, and gas sensor unit. The application of blown-trough pervaporation membrane in a combination with gas sensor used for the 
measurement of methane enables on-line analysis of dissolved gases in water, permits the miniaturization of all system, especially compared to the application of spectrometer of mass. The results presented in this publication are based on our previous data [4], where we optimized the structure of pervaporation membrane used for the separation of dissolved gas from water.

\section{Experiment}

The scheme of the system used for the determination of the concentration of hydrocarbons dissolved in water is presented in Figure 1; photo of cell consisting of tubular pervaporation membrane dipped in water is given in Figure 2.



Figure 1. Scheme of setup used for the determination of concentration of volatile organics in water. cell with water; (2) can with distilled water; (3) tubular selective membrane; (4) cylinder with CH4; (5) pure air generator; (6-8) flow-meters; (9) methane sensor cell; (10),(11) ohmmeter and computer; (12) fume hood ; (13) water mixer; (14) air bubbler.

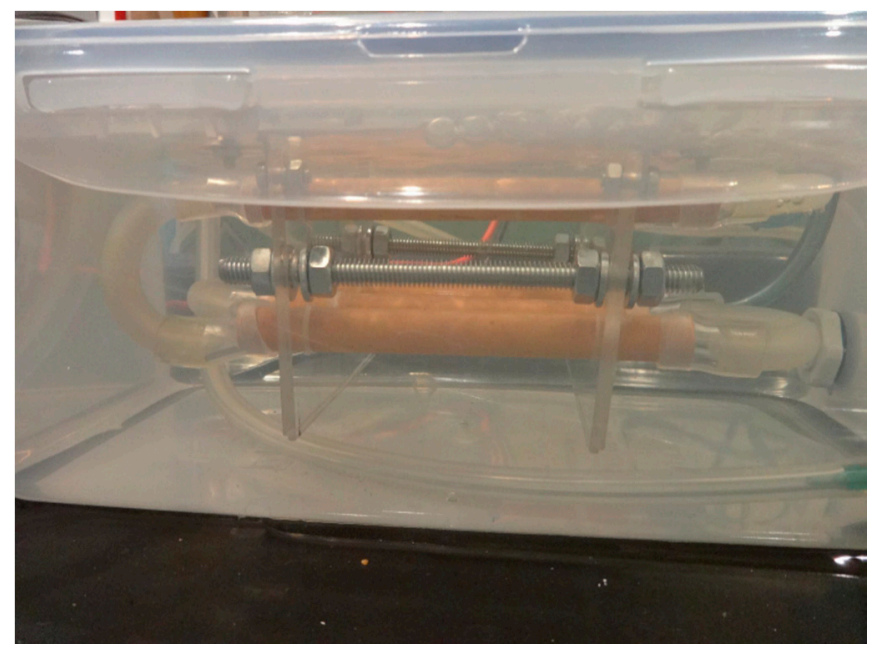

Figure 2. Water cell with hydrophobized porous ceramic tubes immersed in distilled water.

The system consists of tubular membrane permeable for volatile organics and impermeable for liquid water connected to gas sensor cell. The membrane is permeable as well for water vapor, therefore relative humidity of carrier gas in all experiments is close to $100 \%$. Carrier gas flowing through the tube is saturated with volatile organics; volatile organics concentration in carrier gas (purified air) is measured in on-line regime with gas sensor. The membrane is made of porous ceramics; it is hydrophobized by impregnation with fluoropolymer solution or by deposition of thin 
layer (thickness $300 \mathrm{~nm}$ ) of polytetrafluoroethylene (PTFE), obtained by electron beam dispersion of solid polymer in vacuum (Figure 3, [5]).

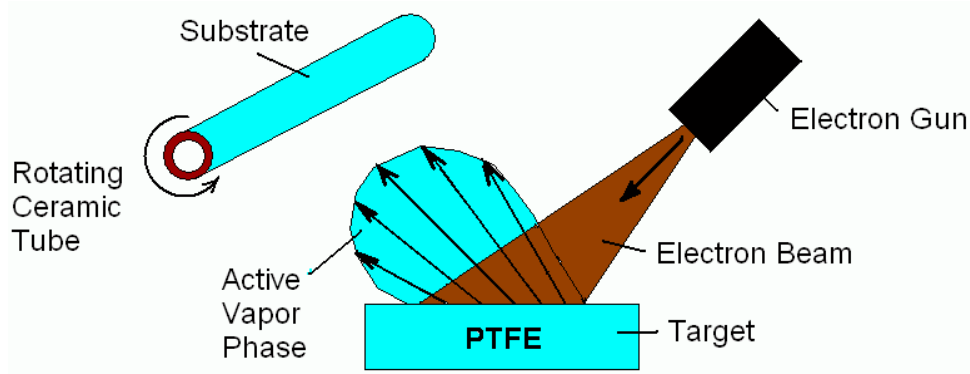

Figure 3. Scheme of experimental setup for electron-beam deposition of hydrophobic coating on porous ceramic tube in vacuum.

In the case of hydrophobization by impregnation, we used fluoroorganic compounds presented in Figure 4. Hydrophobization was performed by complete immersion of porous tube to the hydrophobic liquid. Hydrophobization was completed after $1 \mathrm{~h}$; then, the tube was dried at room temperature for $2 \mathrm{~h}$ and at $100^{\circ} \mathrm{C}$ for $1 \mathrm{~h}$.

The hydrophobic molecules are bonded to the surface of the tube material $\left(\mathrm{Al}_{2} \mathrm{O}_{3}\right)$ by ethoxyl groups enabling perfect adhesion of the coating to the surface of the ceramic material. The thickness of hydrophobic coating corresponds to the size of molecule (single molecule coating) and equals $2 \mathrm{~nm}$.


$+\mathrm{E} \mathrm{OH}$

Figure 4.The structure of hydrophobic coating deposited to the membrane by immersion.

\section{Results and Discussion}

The measurements of the gas response of the system were performed using setup presented in Figure 1. We used membrane unit consisting of 6 ceramic tubes $(1 \mathrm{~cm}$ in diameter and $10 \mathrm{~cm}$ long) connected in series. The gas flow was varied in a large range enabling carrier gas residence time in membrane unit from 10 to 250 s.This residence time influences, obviously, the saturation of gas with methane dissolved in water (Figure 5). In these experiments we used porous ceramic tube with pore size of $10 \mu \mathrm{m}$, and the same ceramic tube, coated with additional nanocrystalline titania layer with $100 \mathrm{~nm}$ pore size.

The sensor response as function of methane concentration in air bubbling through water is presented in Figure 6. The size of pores in porous ceramic tube affects the diffusion of gas through the tube wall. Further optimization of the system will be directed to decrease in thickness of the selective membrane wall and tube diameter, improvement of hydrophobic properties of the membrane to give possibility of on-line determination of volatile hydrocarbon concentration in water. 


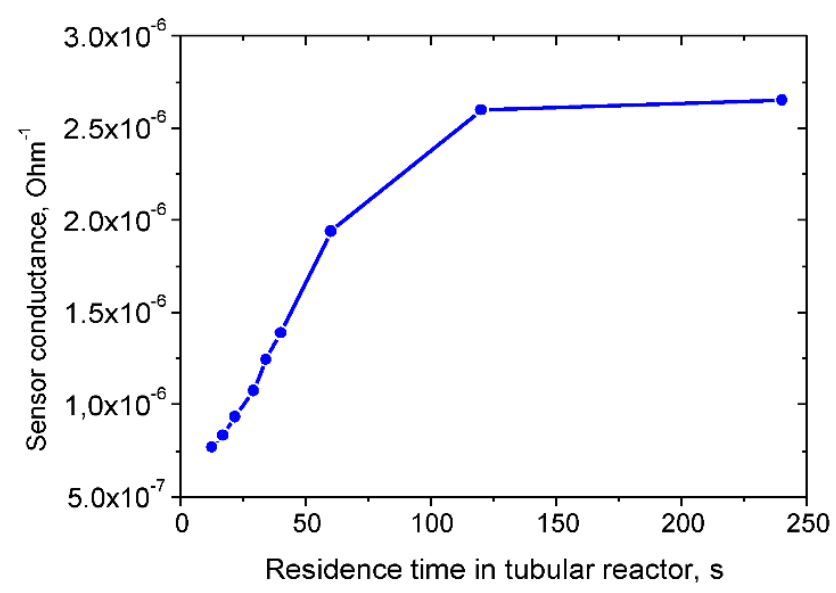

Figure 5. Metal oxide sensor conductivity as a function of carrier gas (air) residence time in membrane unit. Concentration of $\mathrm{CH}_{4}$ in gas bubbled through water is of $1 \%$.

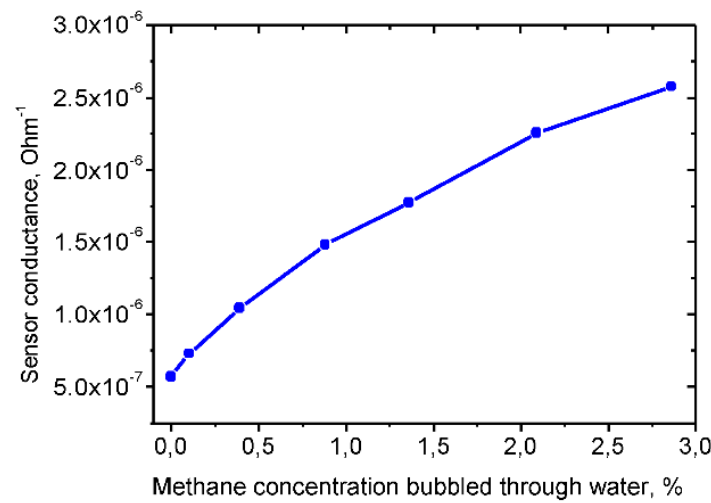

A

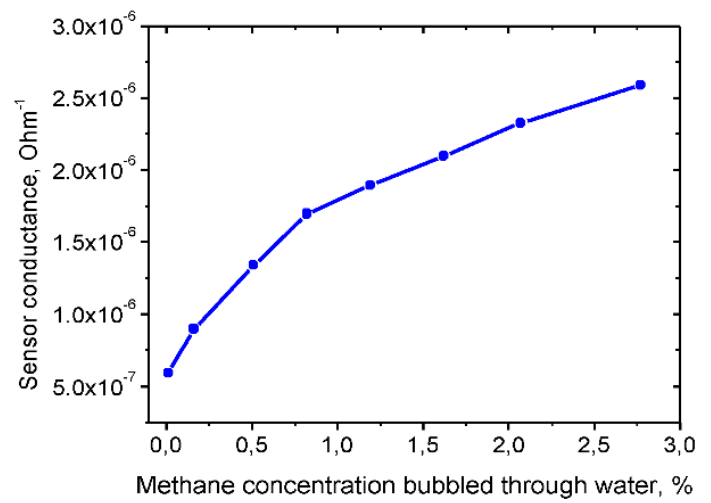

B

Figure 6.Sensorconductivity as a function of methane concentration in air bubbled through water:(A)

Ceramic membrane with pore size of $100 \mathrm{~nm}$; (B) Ceramic membrane with pore size of $10 \mu \mathrm{m}$.

\section{Conclusions}

We developed a prototype of underwater analytical system consisting of tubular pervaporation membrane and gas sensor. Carrier gas flowing through the tube and sensor chamber is saturated with gas analyte and detected by gas sensor. Detection limit of such system can reach $\sim 20 \mathrm{ppb}$ (by mass) at the detection of methane concentration in water.

Author Contributions: A.A.V. formulated the problem and performed main part of the experiments, M.Y.Y. fabricated the experimental set-up, obtained hydrophobic coatings on ceramic membranes and performed the experiments with methane dissolved in water, A.V.S. participated in the experiments and in the discussion of the results.

Conflicts of Interest: The authors declare no conflict of interest.

\section{References}

1. Ritter, S.W.; Lendl, B.; Rosenberg, E. Challenges in the determination of petroleum hydrocarbonsin water by gas chromatography (hydrocarbon index). Fuel 2013, 113, 527-536.

2. Kogan, V.T.; Kozlenok, A.V.; Chichagov, Y.V.; Antonov, A.S.; Lebedev, D.S.; Bogdanov, A.A.; Moroshkin, V.S.; Berezina, A.V.; Viktorova-Leclerc, O.S.; Vlasov, S.A.; et al. Small-Size Mass Spectrometer for Determining Gases and Volatile Compounds in Air During Breathing. Tech. Phys. 2015, 60, 1549-1555.

3. Vasiliev, A.A.; Pisliakov, A.V.; Sokolov, A.V.; Polovko, O.V. Method and Instrument for Continous Determination of Concentration of Gases Dissolved in Water. Patent RF No. 2605819, November, 17, 2016. 
4. Vasiliev, A.A.; Pisliakov, A.V.; Sokolov, A.V.; Polovko, O.V.; Samotaev, N.N.; Kujawski, W.; Rozicka, A.; Guarnieri, V.; Lorenzelli, L. Gas Sensor System for the Determination of Methane in Water. Procedia Eng. 2014, 87, 1445-1448.

5. Kravets, L.I.; Gil'man, A.B.; Yablokov, M.Y.; Altynov, V.A.; Orelovitch, O.L. Formation of composite membranes containing hydrophobic polymer layers by electron-beam sputter deposition. High Energy Chem. 2016, 50, 460-465.

(C) 2018 by the authors. Licensee MDPI, Basel, Switzerland. This article is an open access article distributed under the terms and conditions of the Creative Commons Attribution (CC BY) license (http://creativecommons.org/licenses/by/4.0/). 